\title{
Additive manufacturing for health technology applications
}

\author{
Sven F. KLIMASCHEWSKI, Robert RASCHKE, Mark VEHSE
}

DOI: 10.30464/jmee.2019.3.3.215

Cite this article as:

Klimaschewski S. F., Raschke R., Vehse M. Additive manufacturing for health technology applications. Journal of Mechanical and Energy Engineering, Vol. 3(43), No. 3, 2019, pp. 215-220.

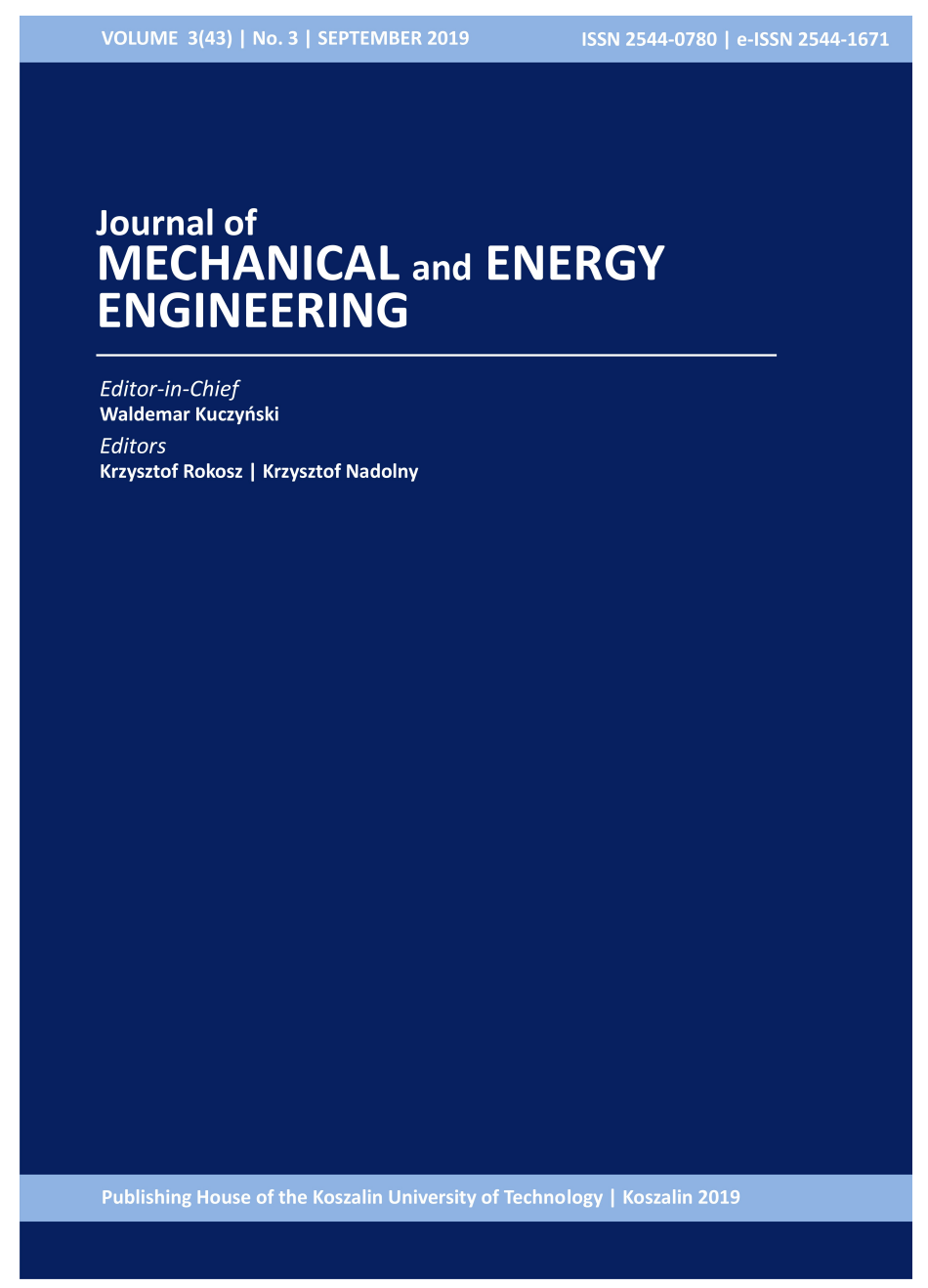

Journal of Mechanical and Energy

Engineering

Website: jmee.tu.koszalin.pl

ISSN (Print): $2544-0780$

ISSN (Online): 2544-1671

Volume: 3(43)

Number: 3

Year: 2019

Pages: 215-220

Article Info:

Received 17 August 2019

Accepted 21 October 2019

\section{Open Access}

This article is distributed under the terms of the Creative Commons Attribution 4.0 (CC BY 4.0) International License (http://creativecommons.org/licenses/by/4.0/), which permits unrestricted use, distribution, and reproduction in any medium, provided you give appropriate credit to the original author(s) and the source, provide a link to the Creative Commons license, and indicate if changes were made. 


\title{
ADDITIVE MANUFACTURING FOR HEALTH TECHNOLOGY APPLICATIONS
}

\author{
Sven F. KLIMASCHEWSKI ${ }^{1}$, Robert RASCHKE ${ }^{1}$, Mark VEHSE $^{1^{*}}$ \\ ${ }^{1}$ Faculty of Mechanical Engineering, CAE \& Engineering Design, University of Applied Sciences Stralsund, \\ Zur Schwedenschanze 15, Stralsund, 18435, Germany, mark.vehse@hochschule-stralsund.de
}

(Received 17 August 2019, Accepted 21 October 2019)

\begin{abstract}
In this study we demonstrate an overview about possibilities in using additive manufacturing for tissue engineering and orthopedic prosthesis. We show the possibilities to produce scaffolds by using a low cost commercial stereolithography system under the use of biocompatible hydrogels like Poly(ethylene glycol) diacrylate. We also demonstrate that it is possible to use a low cost selective laser sintering system to produce individual prostheses to support the healing process in many orthopedic issues.
\end{abstract}

Keywords: additive manufacturing, biocompatible hydrogel, stereolithography, selective laser sintering

\section{INTRODUCTION}

Additive Manufacturing (AM) in the field of health technology offers a wide range of patient individual product applications. For example, on the one hand, it is possible to print implants or their prototypes by using biocompatible materials like biocompatible synthetic polymers, materials of natural origin or biocompatible hydrogels. In this scope, stereolithography [1, 2] or Diode Laser Curing (DLC) [3] are excellent suitable manufacturing processes and they offer extensive possibilities in generating geometries for tissue engineering [4-6]. On the other hand, AM technologies allows a production of individual orthopedic aids [7, 8], especially effective by using selective laser sintering, e.g. [9, 10].

In our group we focus on two applications in health technology: in the field of tissue engineering and in the field of orthotics. In these two directions, we see the possibility of relieving and supporting patient-specific implants during the healing process with patient-specific orthoses. In our vision, both individually implant and individually postoperative orthosis are customized and matched to each other.

\section{MATERIALS AND METHODS}

For research in the field of health technology special requirements are placed on the materials to be used. In principle, all materials should be having a biocompatibility. On a closer view, however, biocompatibility must be de-fined according to the application. When used in orthoses completely different conditions apply than with implants that remain in the organism.

\subsection{Stereolithography (SLA)}

Stereolithography is an AM technique based on photo-polymerization of a resin by using UV laser radiation (e.g. $405 \mathrm{~nm}$ ). In our case we us a commercial printer (Nobel 1.0, XYZprinting, Inc. Taiwan) with some technical modifications, shown in Figure 1. The setup follows the colamm principle with laser irradiation trough a transparent window on the bottom of the chamber [11].

Figure 1 shows the modified Nobel 1.0. The commercial machine setup (fig. 1; A) received in fig. 1; B \& C) a new building platform (9) including a new connector (2) to z-stage. Due to the magnetic mechanism (16) between metallic building platform and connector we are able to dis-mount the platform and also print specific small and filigree samples (8). The chamber (10) was modified geometrical to reduce the resin (5) volume and is fixed by a 3d-printed special unit (19). All other components, like beamline $(6,7,11,12,13)$ or mechanical moving system $(1,3)$ are original components from Nobel 1.0. Also the bottom of the chamber, the optical window $(17+18)$ is made by original material like the chamber from the 
Nobel 1.0 printer. In this way it is possible to use the original detachment mechanism of the system.

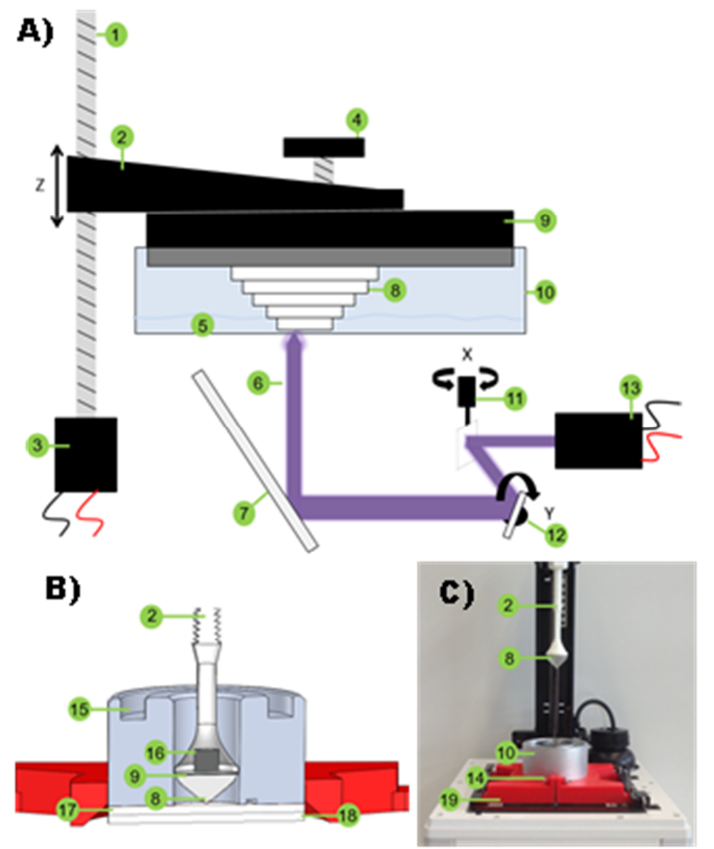

Fig. 1. Schematic principle of the used stereolithography configuration A) machine setup Nobel 1.0; B) CAD data modified chamber + modified building platform; C) photo-graph of the modified setup at Nobel 1.0 including a sample (8)

\subsection{Synthesis of the resin}

The resin is based on Poly(ethylene glycol) diacrylate (PEGDA) with an average molecular weight of Mn 700 bought from Sigma Adrich, Inc.. The PEGDA was inter-mixed for $6 \mathrm{~h}$ at 500 r.p.m. with bis(2,4,6-trimethylbenzoyl)-phenyl- phosphineoxide / 2-hydroxy-2-methyl-1-phenyl-propan-1- one (Omni$\operatorname{rad}$ 2022, IGM Resins B.V.) as photoinitiator (PI) including a subsequent rest period of $1 \mathrm{~h}$. The best resin properties contain a PI content of $0.005 \mathrm{wt}-\%$. To reduce the curing depth on a suitable value, a UV radiation absorber (2,2'-Dihydroxy-4,4'-dimethoxybenzophenone) from TCI Deutschland $\mathrm{GmbH}$ was added in a value between $0.4 \mathrm{mg} / \mathrm{ml}$ and $10 \mathrm{mg} / \mathrm{ml}$. The powder was intermixed at the PEGDA+PI resin for $12 \mathrm{~h}$ at $40{ }^{\circ} \mathrm{C}$ and 1000 r.p.m. PEGDA based resin offers the opportunity of biocompatible and non-toxic implants [16]. The applicability of PEGDA in pharmaceutical research has already been successfully proven in various studies [17].

\subsection{Selective Laser Sintering}

Selective Laser Sintering (SLS) of thermoplastic polymer is a process so called Liquid Phase Sintering or Partial Melting [12]. The powder of polyamide 12 (PA12) is applied in thin layers and partially melted by in-frared laser radiation (e.g. $808 \mathrm{~nm}$ ). In our case we use a system called LISA from Sinterit sp. z o.o.
(Poland) including a heated chamber. Technical changes were not made to this system. With LISA a layer height between $0.075 \mathrm{~mm}$ and $0.175 \mathrm{~mm}$ and a X and Y accuracy of $0.5 \mathrm{~mm}$ is achievable. This production resolution is completely sufficient for the desired applications in orthopedic technology [cf. 13, 14]. When using the SLS with PA12, the orientation in the installation space must be observed. However, the achievable mechanical properties are very suitable for our application [cf. 15].

\section{RESULTS AND DISCUSSION}

The background of the activities in Additive Manufacturing in Health Technologies is the combination of patient individual implants and with orthoses adapted to the patient and the placed implant. So we use stereolithography to develop materials and geometries for implants and selective laser sintering to design orthoses.

\subsection{PEGDA based geometries by SLA}

During the development of the resin, we use a small cone to characterize the layer quality and following to verify the curing parameters (see figure 2). All microscopic pictures in chapter 3 are done by a digital microscope (Keyence VW-9000D). In figure 3 details of such a cone is shown (machine parameters: layer height $100 \mu \mathrm{m}$, step height $500 \mu \mathrm{m}$, laser radiation power $5 \mathrm{~mW}, \mathrm{PI}=0,005 \mathrm{wt}-\%$ ). The lower arrow in fig. 3 ; A) points to a sharp edge with a nearly 90-degree angle between horizontal and vertical planes. In opposite, the upper arrow points on an edge with a "blooming" effect, which results either from the swelling polymerized PEGDA and/or a damage during the post-processing. Figure 3; B) shows an effect within a step which includes a displaced layer (maybe a printing failure). During the processing of the layers, some voxel outside the designed geometry where cured. That probably can happen during the tilting process of the chamber for a new layer (machine dependent). The sample was deformed due to its flexible properties and one or two layers are polymerized outside the designed geometry. After a few layers the machine properties restored the original geometry and the layer are cured in the intended geometry. In addition, Figure 4 shows the layer structure within a step of the cone. The insights gained from the cone experiments serve to develop scaffold or other implant geometries from biocompatible material. A special challenge is to create geometries with fine channels and structures. There, vessels are later to be given the opportunity to grow through the implant in order to be able to supply cells. Also allow the channels an establishment of structures for metabolism. The scaffold in figure 5 is such a structure. Based on a cube with an edge length of approximately $15 \times 15 \times 15 \mathrm{~mm}^{3}$ we demonstrate oval 
and rhomboid channels in different directions (lowest edge length approx. $500 \mu \mathrm{m})$. These structures allow a development of complex implant geometries like e.g. menisci or stent like tubes, see figure 6 .

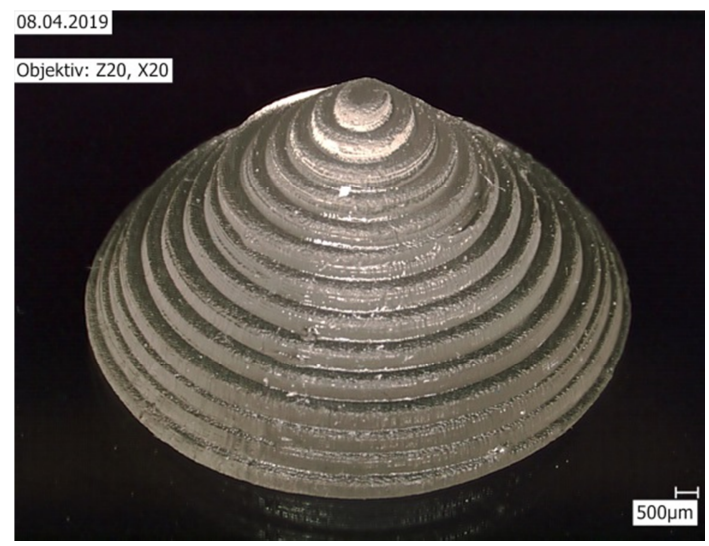

Fig. 2. Sample picture of the reference geometry "cone"

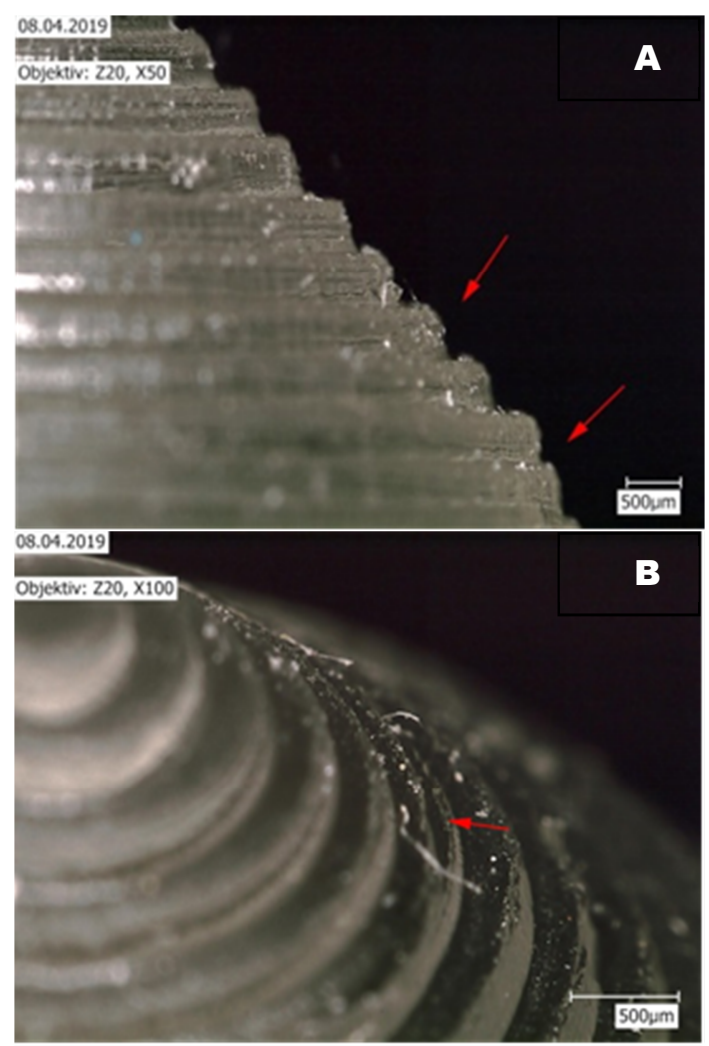

Fig. 3. Sample of the stair-steps of the cone A) upper arrow edge with blooming, lower arrow with relatively sharp edge; B) effect of a displaced layer

\subsection{Orthosis sample}

After an operation or implantation on joints, orthoses are needed in most cases as a supporting structure. Due to this fact, we decide to design $3 \mathrm{~d}$ printable, patient individual orthoses to produce by selective laser sintering. Selective laser sintering enables the generation of complex geometries. This makes it possible to produce very light but stable orthopedic products which can also be adapted exactly to the individual body geometry.

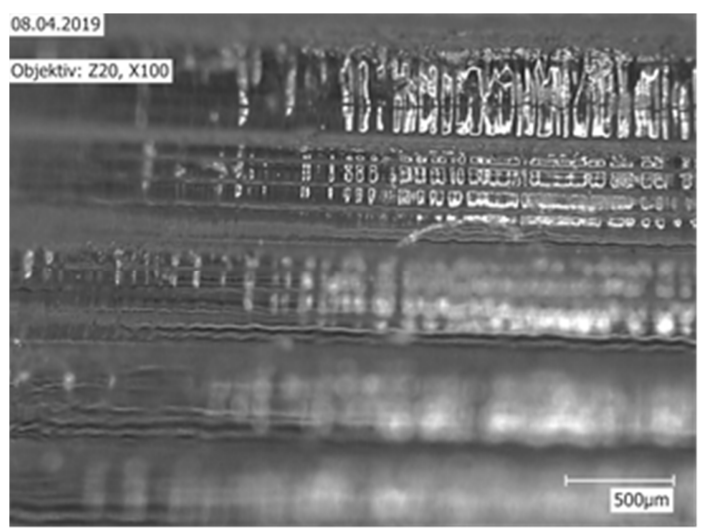

Fig. 4. Details of the layer structure within the steps

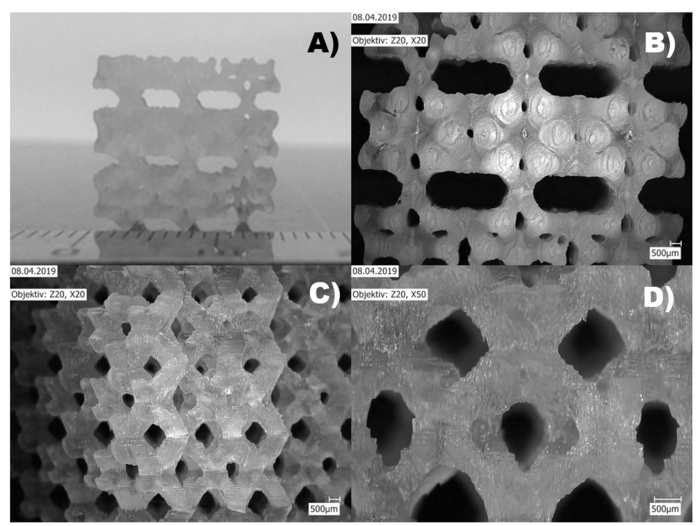

Fig. 5. A) PEGDA based Scaffold with B) horizontal oval channels in $\mathrm{x}$ and $\mathrm{y}, \mathrm{C}$ ) diagonal rhomboid channels and $\mathrm{D})$ vertical rhomboid channels in $\mathrm{z}$ direction (all: 0,006 wt-\% UV radiation absorber)
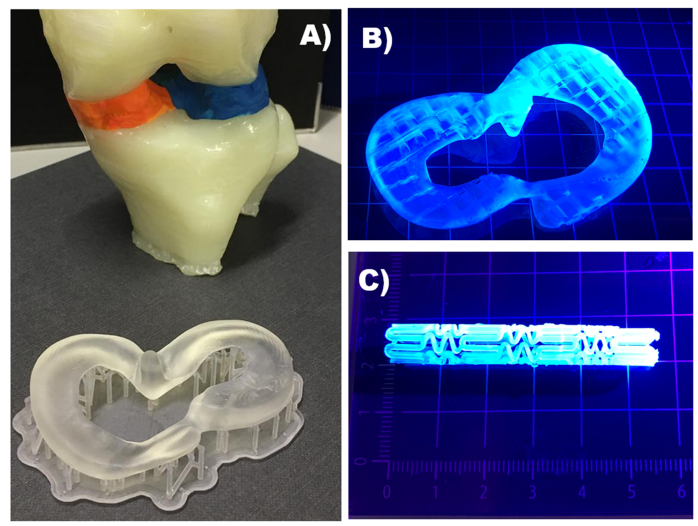

Fig. 6. Examples based on materials science and technical knowledge from the preliminary tests for possible applications; A) + B) possible geometries to replace a meniscus in the knee, C) stent based on polymer 
As a sample we demonstrate the possibilities on a wrist orthosis including a hinge (CAD, see figure 7). In our case, the function of the wrist orthoses focused on the immobilization after fractures or soft-tissue trauma, as well as arthritis. The design is a reverse engineering from a scan of human arm. Reverse engineering technology has already proven itself in orthopedic technology for the manufacture of orthoses [21].
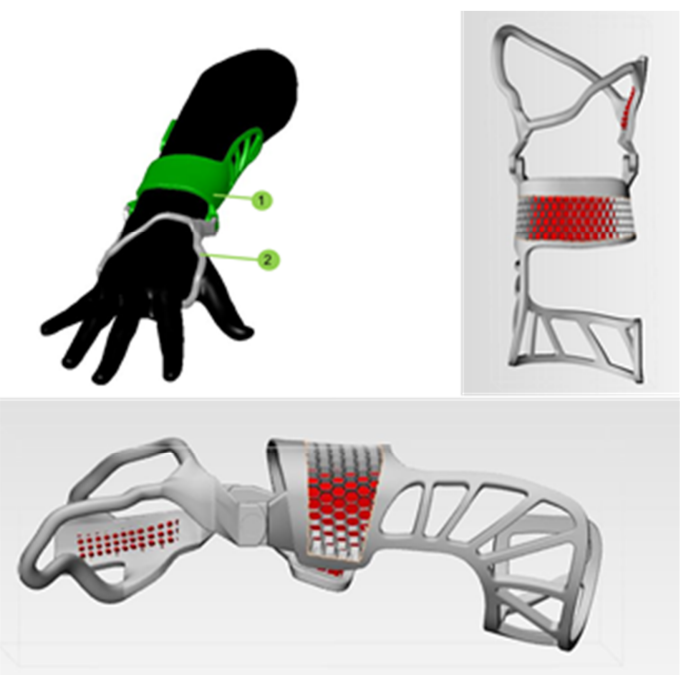

Fig. 7. Geometrical Set (CAD) of a wrist with a hinge and limited movement angle
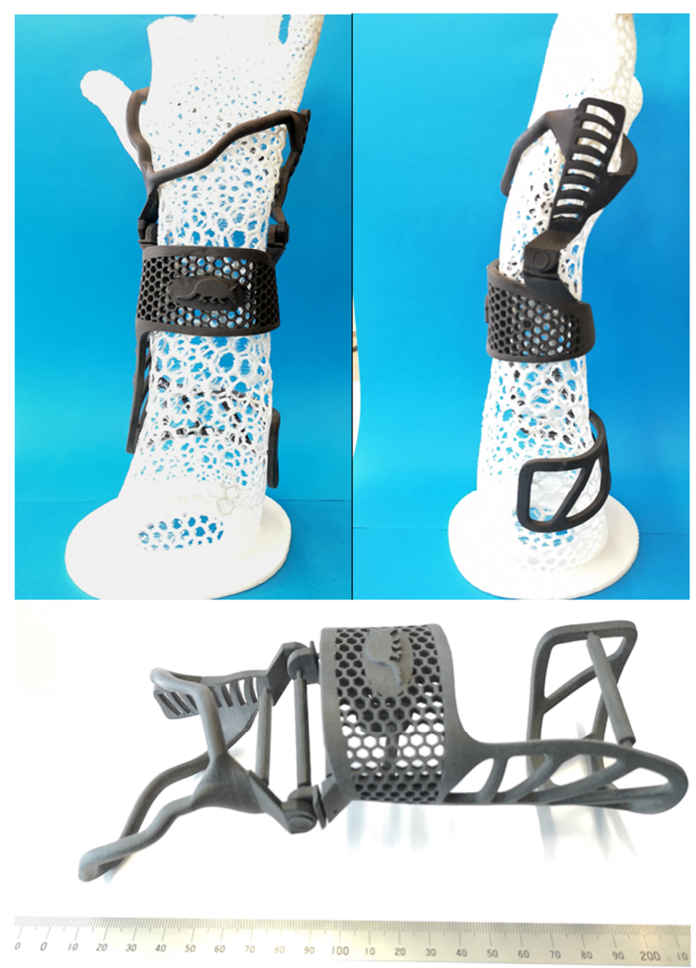

Fig. 8. photographs of 3d-printed (SLS) arm orthoses with a hinge for e.g. immobilization after fractures or soft-tissue trauma
Other possible functions of the wrist orthosis include the treatment of inflammation (e.g. tendovaginitis), postoperative conditions, paralysis, carpal trough syndrome (CTS), wrist pain or the improvement of the function by stabilization and the prophylaxis of contractures and axial deviations [19, 20].

To produce our samples, we used SLS with following parameters: layer thickness $0.125 \mathrm{~mm}$, laser power ratio $1.05 \%$, chamber temperature $178{ }^{\circ} \mathrm{C}$ and a material PA12 (bought directly from Sinterit sp. $\mathrm{z}$ o.o.). In fig. 8 , the result of our test print of the geometrical set from fig. 7 is shown. As can be seen, the orthosis has a light weight structure and fits well to the 3d-printed arm (Replicator Z18, Makerbot, Ink.). The stability of individual segments has not yet reached the desired level. Further studies on compressive and tensile strengths will be carried out.

\section{CONCLUSIONS}

Summarizing the activities, it could be shown that additive manufacturing is a suitable technology to manufacture different patient individual implants and orthoses.

The scaffold printed with the described formula shows that a commercial SLA system makes it possible to generate thin-walled and elastic 3D objects in one production step. The designed lightweight structure (only $\approx 15 \%$ material in vol.) corresponds in structure to the scaffold produced on the SLA system $\left(\approx 0.26 \mathrm{~g} / \mathrm{cm}^{3}\right)$. To develop filigree but also mechanically resilient structures, from our point of view, further tests have to be done in structure design and in addition in chemical composition of the resin. In order to make the sample parts even more filigree, the power intensities of the laser should be gradually increased from $5 \mathrm{~mW}$ to $55 \mathrm{~mW}$ in $5 \mathrm{~mW}$ steps.

The area of application has only been touched on here and, from our point of view, is much more extensive. In further experiments we will improve the material for SLA (PEGDA) and we will do toxicity studies.

Simultaneously we will improve our orthopedic geometries and we will test different materials for SLS to improve stability and durability under a wide variety of using scenarios. The sample in this study can be used to show that an orthosis can be produced without special requirements for the $3 \mathrm{D}$ printer and with basic CAD knowledge. Selective Laser Sintering allows a setup without any supporting structures. The results received with the low cost printer are in a comparable quality as presented in literature [e.g. 13, 14]. We will do further research with different commercially available powder materials with respect to flexibility, durability and mechanical load. 


\section{Acknowledgements}

The authors grateful acknowledge the financial support from the European Union (GHS-17-0022, European Regional Development Fund. Operational Program Mecklenburg-Vorpommern, Germany 20142020 - Investing in growth and employment). The Work by these authors was also financially supported by the internal research project funding 2018 of the Hochschule Stralsund (Int-FoFö2018- 12112401).

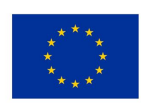

EUROPÄISCHE UNION

Europäischer Fonds für regionale Entwicklung

\section{Mecklenburg $\square$ Vorpommern Mrtut gut.}

\section{DD HOST}

\section{Nomenclature}

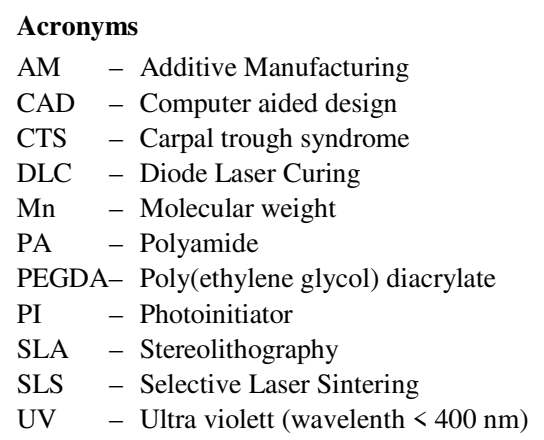

\section{References}

1. Skoog, S.A., Goering, P.L. \& Narayan, R.J. (2014) Stereolithography in tissue engineering, $J$ Mater Sci: Mater Med, Vol. 25, No. 3, pp. 845-856.

2. Cooke, M. N. (2003), et al., Use of stereolithography to manufacture critical-sized 3D biodegradable scaffolds for bone ingrowth, Journal of biomedical materials research. Part B, Applied biomaterials, Vol. 64, No. 2, pp. 65-69.

3. Vehse, M., Petersen, S. \& Seitz, H. (2107) High resolution photo-polymerization technique for fabrication of hydrogel based scaffolds, Biomed. Eng.Biomed. Tech., Vol. 62, No. S1, p 212.

4. Vehse, M. \& Seitz, H. (2014) (Micro-) Stereolithography based on Diode Laser Curing (DLC) and its Potential Applications in Tissue Engineering, BiomedTech, Vol. 59, No. S1, pp. 276-278.

5. Priola, A., et al., (1993) Properties of polymeric films obtained from uv cured poly (ethylene glycol) diacrylates, Polymer, Vol. 34, No. 17, pp. 3653-3657.

6. Kalakkunnath, S., et al. (2006), Viscoelastic characteristics of UV polymerized poly (ethylene glycol) diacrylate networks with varying extents of crosslinking, Journal of Polymer Science Part B: Polymer Physics, Vol. 44, No. 15, pp. 2058-2070.

7. Yu-an, J. et al. (2015) Additive Manufacturing of Custom Orthoses and Prostheses - A Review. Procedia CIRP, Vol. 36, pp. 199-204.

8. Mavroidis, C. et al. (2011), Patient specific ankle-foot orthoses using rapid Prototyping, Journal of NeuroEngineering and Rehabilitation, Vol. 8, No. 1 pp. $1-11$.
9. Rogers, B. et al. (2007) Advanced Trans-Tibial Socket Fabrication Using Selective Laser Sintering, Prosthetics and Orthotics International, Vol. 31(1), pp. 88-100.

10. Kai C. C. (2000), et al., Facial prosthetic model fabrication using rapid prototyping tools, Integrated Manufacturing Systems, Vol. 11, No. 1, pp. 42-53.

11. Jacobs, P. F. (1992) Rapid Prototyping \& Manufacturing - Fundamentals of Stereolithography, 1st ed., Society of Manufacturing Engineers, Ed. Michigan: Dearborn, 5. Print.

12. Kruth, J-P. et al. (2005) Binding mechanisms in selective laser sintering, Rapid Prototyping Journal, Vol. 11, No. 1, pp. 26-36.

13. L. Muraru, L. et al. (2010) SLS nylon 12 characterization through tensile testing and digital image correlation for finite element modelling of foot and ankle-foot orthoses, 21st Solid Freeform Fabrication Symposium, Austin, TX, USA, pp. 828-833.

14. Kozlovsky, K. et al. (2018), Mechanical Properties of Reused Nylon Feedstock for Powder-bed Additive Manufacturing in Orthopedics, Procedia Manufacturing, Volume 26, pp. 826-833

15. Nelson, JA, et al. (2014), Effects of scan direction and orientation on mechanical properties of laser sintered polyamide-12, International Journal of Advanced Design and Manufacturing Technology, Vol. 7, No. 3, pp. 19-25.

16. B. Mellott, M., Searcy, K. \& Pishko, M. (2001) Release of protein from highly cross-linked hydrogels of poly(ethylene glycol) diacrylate fabricated by UV polymerization. Biomaterials, Vol. 22, pp. 929-941.

17. Wang, J., et al. (2016), Stereolithographic (SLA) 3D printing of oral modified-release dosage forms, International journal of pharmaceutics, Vol. 503, No. 12, pp. 207-212.

18. Rekowska, N., et al. (2008), Thermomechanical properties of PEGDA and its co-polymers, Current Directions in Biomedical Engineering, Vol. 4, No.1, pp. 669-672.

19. Gutsfeld, P. et al. (2016) Orthesen in der Unfallchirurgie. Trauma und Berufskrankheit, Vol. 18, No. 2, pp.116124.

20. Specht, J., Schmitt, M. \& Pfeil, J. (2008) Technische Orthopädie - Orthesen und Schutzeinrichtungen, p. 95 Springer-Verlag Berlin Heidelberg.

21. Tosheva, Y. E. et al. (2005); Reverse engineering and rapid prototyping for new orthotic devices, Intelligent Production Machine and System - The 1st Virtual International Conference on Intelligent Production Machines and Systems, pp. 567-572. 


\section{Biographical notes}
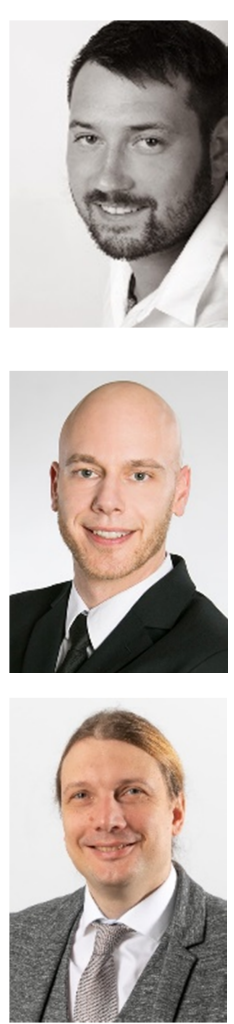

Sven F. Klimaschewski received his

B.Eng. degree in Mechanical Engineering in 2019. He is an undergraduate assistant at the $\mathrm{Lab}$ of Engineering Design and Product Development at HOST Hochschule Stralsund, Germany. He is responsible for PEGDA based research and stereolithography.

Robert Raschke received his B.Eng. degree in Mechanical Engineering in 2019. He is an undergraduate assistant at the Lab of Engineering Design and Product Development at HOST Hochschule Stralsund, Germany. He is responsible for all research activities around selective laser sintering.

Mark Vehse received his Dipl.-Ing. (FH) degree in Physics Engineering in 2001 and next his M.Sc. degree in Optical Engineering and Photonics (2003) from HAWK Hildesheim/ Holzminden/ Göttingen, Fakultät Naturwissenschaften und Technik. After that, he was a research associate at University of Siegen for nearly one year (2004). After 5 years at the headlamp specialist Automotive Lighting Reutlingen $\mathrm{GmbH}$ (2005-2009), he returned to research at the University of Rostock. There he completed his research work with a doctorate (Dr.-Ing.) at the Faculty of Mechanical Engineering and Marine Technology with a focus on additive manufacturing for medical technology in 2014. Subsequently, he was head of Development, Prototyping and Engineering Design at GRASS Hetal-Werke Franz Hettich GmbH \& Co. KG in Alpirsbach. Since 2014 he is a full professor for Engineering Design and Product Development at HOST Hochschule Stralsund, Germany and also the head of the Lab of Engineering Design and Product Development at HOST. He led several research projects, presented the results of his work so far at 8 international and 6 national conferences, published more than 25 scientific papers in international and national journals as well as conference proceedings. He is also an inventor in 12 national and international patents and Mark Vehse received 2 national innovation awards. 